Revista de la red interuniversitaria de estudios sobre las literaturas rioplatenses contemporáneas en Francia

$20 \mid 2019$

Situación

\title{
El acecho animal a la poesía argentina contemporánea
}

La traque animale à la poésie argentine contemporaine

The Animal Stalking to Contemporary Argentine Poetry

\section{Elena Campero}

\section{(2) OpenEdition}

\section{Journals}

Electronic version

URL: http://journals.openedition.org/lirico/8408

DOI: $10.4000 /$ lirico.8408

ISSN: 2262-8339

\section{Publisher}

Réseau interuniversitaire d'étude des littératures contemporaines du Río de la Plata

\section{Electronic reference}

Elena Campero, «El acecho animal a la poesía argentina contemporánea », Cuadernos LIRICO [En

línea], 20 | 2019, Publicado el 10 julio 2019, consultado el 02 junio 2020. URL : http://

journals.openedition.org/lirico/8408; DOI : https://doi.org/10.4000/lirico.8408

This text was automatically generated on 2 June 2020 .

\section{(c) $(1) \odot$}

Cuadernos LIRICO está distribuido bajo una Licencia Creative Commons Atribución-NoComercial-

SinDerivar 4.0 Internacional. 


\title{
El acecho animal a la poesía argentina contemporánea
}

\author{
La traque animale à la poésie argentine contemporaine \\ The Animal Stalking to Contemporary Argentine Poetry
}

Elena Campero

\section{Tirones de una fuerza poderosa}

1 “Agarrate llegó la poesía” (Mairal 2013: soneto 15). Esta es la advertencia que recibe el poeta-recluta Ramón Paz cuando siente por vez primera al "surubí gigante con su furia" en El gran surubí (2013) del escritor argentino Pedro Mairal. A partir de ese momento, "surubí" y "poesía" se imbrican para no separarse jamás en el poema-río conformado por este conjunto de sesenta sonetos ${ }^{1}$. En tanto se trata de una re-escritura del Martín Fierro (1872 y 1879) de José Hernández, este Moby Dick rioplatense podría simplemente pensarse en tanto retorno acuático del animal decimonónico ${ }^{2}$. Sin embargo, plantear un regreso nostálgico de este estilo traiciona de raíz la naturaleza meta-poética de esta obra de Mairal. Justamente, los coletazos del surubí furioso alcanzarán e impactarán bifrontemente las orillas de la producción literaria nacional.

2 En esta versión, el poeta Ramón Paz y sus amigos son reclutados a la fuerza para pescar en el Río de la Plata al surubí guazú. Al re-escribir el texto clásico de la gauchesca, Mairal recupera la pregunta por la identidad o el ser (Ludmer 120), para pensarla en relación a la figura del poeta: ¿qué significa ser poeta? De esta manera, Mairal redefine al poeta a través de su devenir surubí monstruoso. Por eso, cuando el cuerpo del gigantesco pez imanta al poeta Ramón Paz y juntos emprenden una travesía singular río arriba, la obra de Mairal lleva a cabo una operación literaria mucho más compleja: socava los cimientos de la tradición literaria nacional y, simultáneamente, perfila un nuevo horizonte para la poesía argentina en el cual restituye el impetuoso fluir de la palabra ${ }^{3}$. Al hacerlo, animal, muerte y poesía se fusionan en una escritura que apuesta a la fuerza de la palabra y que hace de la libertad su premisa por antonomasia. De allí la trascendencia que dicha obra adquiera dentro del campo literario argentino 
contemporáne ${ }^{4}$. Es más, este poemario de Mairal se vuelve una referencia obligada para el conjunto de poemarios a analizar en este ensayo.

3 El surubí se despliega así ostentoso, llamando la atención sobre sí; se vuelve puro brío monstruoso en la corriente metamórfica del lenguaje. Esta irrupción del surubí no constituye un caso único, aislado en la esfera cultural de la región. Como bien señala Gabriel Giorgi en Formas comunes. Animalidad, cultura, biopolítica (2014), dentro de la tradición cultural latinoamericana el animal funcionó durante mucho tiempo en tanto “[...] un revés sistemático y otro absoluto de lo humano" (11) intrínsecamente ligado en el imaginario al salvaje, al bárbaro, al indisciplinado. Sin embargo, desde la década del sesenta, es evidente "una contigüidad y una proximidad nueva con la vida animal" (11) producto de una modificación del lugar que ocupa el animal dentro de la cultura y un énfasis en todo aquello concerniente al cuerpo:

El animal que había funcionado como el signo de una alteridad heterogénea, la marca de un afuera inasimilable para el orden social y sobre el que se habían proyectado jerarquías y exclusiones raciales, se clase, sexuales, de género, culturales- ese animal se vuelve interior, próximo, contiguo, la instancia de una cercanía para la que no hay "lugar" preciso y que disloca mecanismos ordenadores de cuerpos y de sentidos (13).

4 Ahora bien, tampoco puede pasarse por alto que "[e]l animal tiene secretos que, a diferencia de los secretos que guardan las cuevas, las montañas y los mares, están específicamente dirigidos al hombre" (Berger 2001: 11). Ramón Paz debe esperar hasta el final de su travesía para descubrirlo. Develar el secreto de la poesía, que tiene el surubí reservado para Paz, implica metamorfosearse en otro muy distinto al que se era: devenir surubí. Mairal caracteriza al poeta como un sujeto que se deja llevar y atravesar por una fuerza descomunal, cuyo único límite es la muerte. Por eso, en El gran surubí, el poeta que Ramón Paz era debe morir. El pez gigantesco se ofrece entonces como arrebato bestial, como fuga para un poeta que ha perdido todo recuerdo de esa fuerza monstruosa que es la poesía, que es la palabra. Cuando esto ocurre, es arrojado hacia otros seres y es en esa multiplicidad de cuerpos heterogéneos- humanos y animalesque se halla a sí mismo en tanto poeta.

5 Al re-semantizar lo que significa ser poeta, la novela-poema de Mairal se revela como obra clave que no solo reflexiona acerca de la práctica poética hoy en día, sino también despliega algunos de los nudos articuladores animales, muerte y palabra poética sobre los cuales la escritura se yergue en otros proyectos poéticos publicados en los últimos diez años. Si desde un principio como plantea Giorgi "la literatura argentina ha hecho de los animales muertos umbral de interrogación sobre el que se cruzan sentidos a la vez estéticos, históricos y políticos" (2011b: 3), la poesía argentina de los últimos tiempos vuelve a hacerse eco de estas variables para barajarlas a su manera.

6 Me interesa entonces pensar los poemarios Abejas (2009) de Alejandro Crotto, Zoo (2009) de Anahí Mallol y El arte de silbar (2014) de Sonia Scarabelli en ese nuevo horizonte para la poesía anunciado por el texto de Mairal ${ }^{5}$. Examino entonces cóme en estas tres obras la palabra poética, cercada siempre por la experiencia límite de la muerte, encalla en esos cuerpos animales para decirse. Tal como el surubí para Ramón Paz, planteo que son los animales- esos otros omnipresentes- quienes garantizan la posibilidad de enunciación misma para la poesía cuando la muerte ronda. De esta manera, en cada uno de los poemarios, estas tres variables se entrecruzan para delinear una trayectoria particular: Crotto enfatiza la reanimación de la voz poética (su necesidad de volverse otra) impulsada por los animales, Mallol se centra en la experiencia de la muerte a 
partir de animales varios, mientras que Scarabelli plantea cómo se puede burlar esa muerte a partir de un idioma animal. Al llevar adelante estos recorridos, Crotto, Mallol y Scarabelli hallan en esos animales esa tan ansiada expresión que puede- todavía hoy en día coletear furiosamente en la poesía.

\section{El inquietante zumbido de las abejas}

7 No es casual que el título del poemario, Abejas (2009), traiga a colación la escena final del poema "Chaco"; en la palangana verde con algo de agua, se ha formado una plataforma de tres centímetros de abejas ahogadas sobre la cual las vivas se apoyan para beber y así escapar del sofocante calor provincial:

alguien la [a la palangana] había dejado con un poco de agua, y estaba toda llena

de abejas, tres centímetros de abejas ahogadas,

las primeras hundidas y luego encima más

hasta llegar al aire en que zumbaban dando círculos

cientos frenéticas, furiosas,

parándose de a ratos en los cuerpos de las muertas

para un poco de esa agua (18).

La escritura de Crotto descubre este zumbido persistente, imposible de olvidar, para encallarse allí: en esa frontera, donde la vida misma se juega, la melodía desesperada de las abejas existe gracias a esos cuerpos sin vida, flotantes. Abejas da cuenta así de cómo ese zumbido puede eventualmente devenir poesía en boca de ese sujeto lírico en vías de reanimarse. En este sentido, los animales- pertenecientes en su mayoría al ámbito rural se despliegan en la colección entre estos dos polos, vida y muerte, ofreciéndose como materia pura, venerable, "difícil" (10). Al hacerlo, cumplen un papel clave en ese proceso de reactivación de la voz poética, exigido en el poema inaugural "Pido mi puesto" y que concluye con el último texto de la colección.

9 En este poema inaugural, el sujeto lírico pide despertar e integrarse a este orden de la materia. Exige así que otro le frote menta y nieve en los ojos, que le desprenda las costras de óxido del cuerpo, que le tenga de los hombros, para luego restregarle limón en las pupilas. Y que dicha operación vuelva a repetirse. "Porque pido mi puesto, despertar" (7), afirma en el verso final. Reclama adoptar medidas extremas- todas concernientes al cuerpo- para volver a sentirse vivo, despierto; boga por un nuevo modo de ver, que refleje ese estar en el mundo.

10 Los animales, insectos y plantas no tardan entonces en aparecer: las palomas cazadas que penden de un alambre, el cordero degollado y colgado de una pata, el animal preñado que respira mientras duerme, la mariposa revoloteando del tallo al yuyo, el tronco del tilo transitado por una hormiga tempranera, entre otros. En su gran mayoría, las escenas seleccionadas se suceden sin reflexión o comentario alguno; es decir, no hay registro del impacto ejercido sobre la voz poética ${ }^{6}$. Anclados a la muerte o rebosantes de vida, esos cuerpos simplemente se exhiben, demandan ser tenidos en cuenta, cuestionando esa voz inicialmente adormecida.

11 Los animales delimitan así una escena, saturada de vida o muerte, cuyo protagonista es ese cuerpo vuelto espectáculo, que llama la atención sobre sí en tanto materia: "brillan los cuerpos [de las palomas cazadas] en el aire, al sol; la vida es material, y la materia / es difícil, sagrada" (10). Ahora bien, estas trayectorias delineadas por los animales tienen su anverso en la esfera humana. Así, por un lado, tenemos los cuerpos todavía 
tibios de estas palomas cazadas, desplumadas y destripadas que titilan a plena luz del día. Por otro, en el poema "El entierro de Guillermo Martínez", también se disecciona (o "destripa") la historia de vida del cuidador del campo familiar a través de sinécdoques basadas en su cuerpo. Es más, tal como en "La palomas", la voz poética cierra este poema con el cuerpo gastado de Martínez encontrado sin vida bajo el sauce que ahora está enterrado "acostado y envuelto en arpillera hasta los hombros" (39). Estas experiencias, comunes a humanos y animales, en las cuales se privilegia el cuerpo, se repiten, insisten por colarse en la práctica poética de Crotto.

Otras veces, en ese vaivén entre vida y muerte, animales y humanos se confunden adrede. Por ejemplo, "En las haras de Vadarkablar" se introduce la yegua alazana en celo, lista para reproducirse. Unos poemas después es la mujer embarazada de "Cargada" quien es puesta en un primer plano. La selección léxica "preñada", "frena", "resopla", "fuerte", "cargada"- insinúa se trata de la yegua; sin embargo, el hecho de que "crispada se agarra con las manos" (19) no deja margen de duda. Estos instantes de indeterminación, vuelven a repetirse en "Le hablo a su cuerpo que duerme" para mantenerse hasta el final: no sabemos si ese "animal desparramado que respira" es su pareja embarazada o la yegua. Estas experiencias, sostenidas desde los cuerpos (inertes o no), bogan por inscribir un momento de indeterminación donde no importa quién transita la experiencia sino más bien que se trata de un destino compartido. $Y$ es, en ese destino compartido con otros seres, que la voz poética se despierta: por eso, le "habla" al cuerpo palpitante de vida ${ }^{7}$.

Ya en el último poema "Verano", el sujeto poético puede reclamar como suyo el tronco de tilo, con su copa estirándose hacia el cielo, que invita a la hormiga laboriosa a recorrerlo: "Este es mi cuerpo en la mañana, vivo, / el material encanto" (41). El deseo inicial de reanimación se ha cumplido. Devenido en su entorno natural, la voz poética también puede arrogarse ese persistente zumbido. Desde esa zona liminar en la cual se articula, la palabra poética zumba, recordando esos cuerpos antes rozados. Crotto apuesta así a una práctica escrituraria que intuye que "[...] en esta levadura / que de los huesos secos saca abejas, miel / multiplicada [...]" (21). Por eso, cuando observa a su bebé de 5 meses de gestación en la ecografía, el zumbido irrumpe a más no poder para volver ese cuerpito un "enjambre" (23) que invita a habitar el verso

\section{La fragilidad de sabernos presa}

14 Si, por una parte, el título y el epígrafe ${ }^{9}$ del poemario Zoo (2009) de Anahí Mallol parecieran encasillarlo dentro de la tradición del bestiario ${ }^{10}$, por otra, su dedicatoria ${ }^{11}$ sugiere una colección lúdica, liviana, simple con esos lectores niños en mente. La propuesta de Mallol juega con estas posibilidades, para dirigirse en otra dirección. Los animales se suceden así en un vasto catálogo de escenas cotidianas donde los especímenes domésticos conviven con los salvajes, sujetos todos al inevitable ciclo vital ${ }^{12}$ :

$-5-$

aplastado derrama

las entrañas secas y suntuosas

sobre el calor del asfalto

impúdico el sapo

a la hora de la muerte 
se pierde y abandona

su ocasión de fascinar

de repugnar

en la humedad

vidriosa de la piel (13).

Aquello que sostiene estas instantáneas es un juego de miradas-no correspondidas y correspondidas- donde animal y humano se solapan en esa fragilidad de la existencia. Desde su posición de observadora, la voz poética se abalanza sobre ese variado universo animal como si intentara postergar o mitigar la mirada perruna, atiborrada de muerte, con la cual la obra se cierra. Antes de hacerlo, la voz poética expresa su deseoimposible de sostener de evitar todo aquello que la vuelva más vulnerable:

un caballo
parado
debajo de la lluvia
como si no lloviera
así quiero estar:
desnuda entera
debajo de la lluvia
como si nada
como si nadie
me hubiera
tocado nunca
haciéndome más frágil (9)

Desde hace tiempo ya, el debate en torno a la fragilidad ha estado en el centro de discusión, atravesando diferentes disciplinas. Es más, cuando Derrida reflexiona acerca de la pregunta “qquién soy?", insiste- siguiendo los planteos de Bentham- en cuán crucial es para la tradición filosófica occidental preguntarse si los animales pueden sufrir:

Poder sufrir no es ya un poder, es una posibilidad sin poder, una posibilidad de lo imposible. Aquí se aloja, como la manera más radical de pensar la finitud que compartimos con los animales, la mortalidad que pertenece a la finitud misma de la vida, a la experiencia de la compasión, a la posibilidad de compartir la posibilidad de esta im-potencia, la posibilidad de esta imposibilidad, la angustia de esta vulnerabilidad y la vulnerabilidad de esta angustia (2008: 44).

17 Sin embargo, a la voz poética le será imposible mantenerse al margen de este sufrimiento. La muerte- que encarna la fragilidad en su máxima expresión- se vuelve una experiencia recurrente, imposible de cancelar. Por eso, una y otra vez, las trayectorias delineadas por los animales aproximan la escritura de Mallol al límite de ese abismo, indagando "qué es lo que hay / del otro lado / qué es lo que / hace frontera" (11). La muerte irrumpe así como una amenaza constante, siempre lista para emboscar a su próxima víctima: "no saber lo que hay / ahí afuera / lo que acecha / y se cuela / por la más mínima raja: / a la vuelta de la esquina / la muerte el amor / como si nada" (14). Esta cercanía de la muerte todo lo pone en jaque, hace de ese sujeto poético, que intenta (infructuosamente) ser observador, protagonista de esas vidas animales. En este sentido, reiteradas veces sus impresiones, saber o presunciones tienden a colarse a la hora de describir la escena animal. Cuando esto sucede, la voz poética se vuelve partícipe de este destino animal y termina arrastrándose al corazón de una fragilidad irrefutable: 


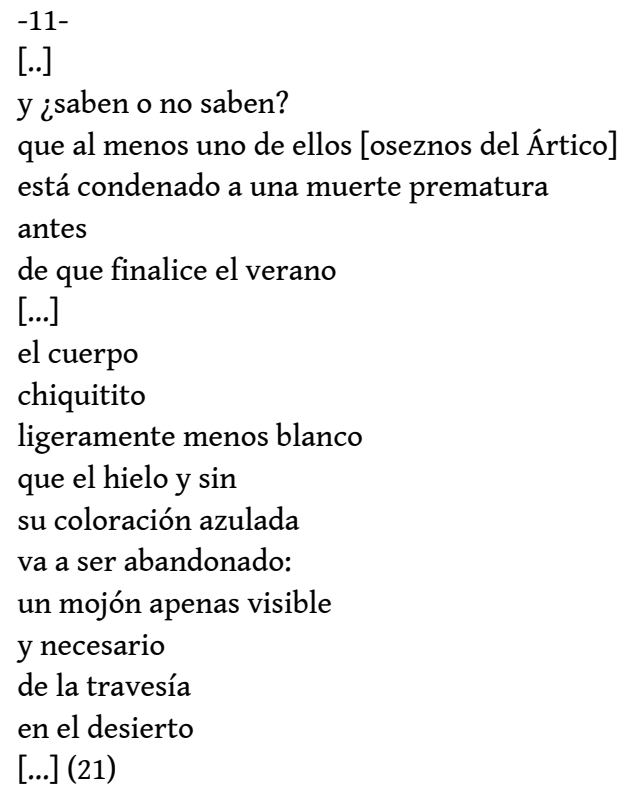

Otras veces, lo humano presiona para imbricarse en la experiencia animal. Por ejemplo, al humanizar el accionar animal cuando se afirma que la libélula "[...] espía /ansiosa hastiada / la franja que trasluce la mampara / del vestidor de las chicas" (10). En otros casos, este vínculo entre humanos y animales se refuerza a través de comparaciones explícitas: "perezoso / como un chico cualquiera / un osezno de grizzly espera" (44). Es decir, en el corazón mismo de la experiencia animal late lo humano, y viceversa.

Es más, en los poemas “4", “7”, “9”, "19” y "24" el nombre del animal tarda en ofrecerse, se posterga igual que la mirada del perro moribundo e igual que la muerte misma- a modo de adivinanza. Vacíos de agente, los versos permanecen libres, a la espera de cualquier ser, que reclame esa experiencia para sí. Las vivencias se ofrecen así en tanto comunes para todo ser viviente: están allí a la espera de quien pueda, deba o desea transitarlas.

Podría entonces afirmarse que los animales retratados en Zoo son apresados por la mirada de un sujeto poético perseguido por el persistente recuerdo de otra mirada, imposible de erradicar: la de un perro atropellado en un suburbio de las calles de Medellín. Esa mirada perruna, encontrada fortuitamente, se cristaliza en el umbral mismo de la muerte; o, en el último poema de la colección, que también es la muerte. Desde el fondo del poemario, la mirada del perro moribundo y abandonado se abalanza implacable sobre el sujeto poético, cargando también con su futura muerte:

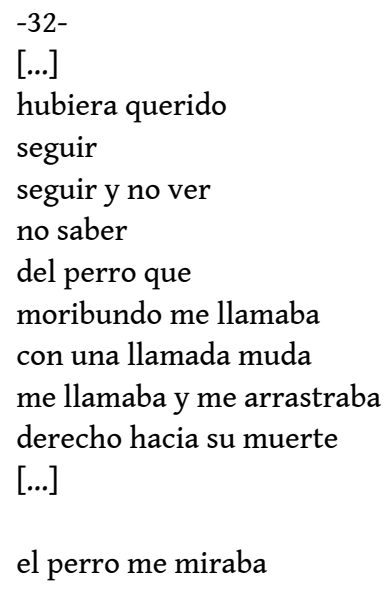




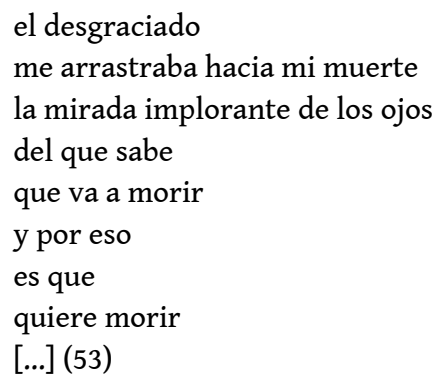

$21 \mathrm{Si}$, por un lado, como señala Cragnoli, "es la muerte la que deconstruye la soberanía de la subjetividad, y es la muerte la que nos acomuna con el resto de los vivientes, entre ellos, los animales" (25). Y, por otro, al mirar a un animal, "[e]l hombre toma conciencia de sí mismo al devolverla [la mirada del animal]" (Berger 2001: 11). No es casual entonces que se trate de uno de los escasos momentos en los cuales la mirada animal y la humana coinciden. Siguiendo los planteos de Julieta Yelin en La letra salvaje (2015), aquí se produce ese encuentro posible del hombre con el animal, sin anular las diferencias, creando un espacio de transición o zona común entre ambos:

Un lugar ni hombre ni animal que, sin embargo, es- en un momento imposible de medir, relatar o fotografiar habitado por ambos, que se sitúa exactamente entre ambos. Ya sea un cruce de miradas, en una metamorfosis, en la experiencia de lo terrorífico o lo siniestro. El vínculo hombre-animal es problematizado y algo del orden de lo animal aparece íntimamente vinculado a lo humano (Yelin 117).

No se trata de la muerte consumada del sapo sobre el asfalto o de la muerte futura del osezno (20) y las tortuguitas (25): es la inminencia de la muerte, que todo lo colma, que no deja resquicio de esa mirada libre. Esta "llamada muda" (53) de la mirada, insuflada de muerte, convoca a la palabra poética: abandona el silencio para volverse poema. No hay forma de escapársele: "al perro le quedaba / como a Alex o a mí / una frontera única" (54). En este sentido, la voz poética es consciente "que esa mirada / me va a acompañar / viva / hasta que encuentre / el sicario compasivo / que decida / a mí también borrármela" (54). Y, por ende, la muerte también atosigará la escena de escritura de Mallol hasta el final de sus días, acorralándola hasta el borde mismo de ese abismo. La voz poética, esa cazadora de escenas animales, termina así cazada: esta "frontera última" es la que delimita el espacio de enunciación sobre el cual se yergue Zoo. En este sentido, el sujeto lírico vendría a convertirse en un ejemplar más de su propio muestrario.

Ahora bien, en el poema "18", tras ser deglutida por una serpiente, el sujeto lírico arremete contra ese silencio absoluto de la muerte. Se trata del único otro momento dentro de la colección donde humano y animal entrecruzan miradas: "hipnotiza: ése es su poder / más fuerte que el veneno / atraer la mirada" (32). Con la muda de piel "estaré cumplida" (33), sentencia el sujeto lírico. Devenido ahora en dragón o serpiente, "el cuerpo circuló / el prestigio de los animales míticos / su pura materia de silbido / de leyenda" (33). Esa voz poética, vuelta presa y víctima, es ese silbido que resuena desde siempre en el corazón mismo de la literatura. Por eso, no sorprende cuando en el penúltimo poema “31", por única vez en la colección, el yo lírico escarabajorinoceronte toma la palabra para auto-celebrar su capacidad de conmoverse: "cuando muera / nadie podrá decir / que pasé / incólume ante la belleza / la premonición y el terror" (51). Escondida tras ese caparazón duro y resistente, la voz poética animal habla para asumir la vida en todo su esplendor y en toda su fragilidad. 


\section{La lengua-silbido del afuera}

24 El arte de silbar (2014) de Sonia Scarabelli guarda, bajo la forma de silbido, un secreto que solamente conoce el animal. "Silbo y al rato un eco se desprende, / como si llegara alto va y se queda / flotando en el aire" (12), afirma el sujeto poético mientras recuerda a su padre fallecido. La respuesta no tardará en llegar articulada a partir de la lengua de los animales.

Con la muerte del padre, silbar- una de esas destrezas legadas por el progenitor al sujeto poético femenino y sus hermanos- deviene un lenguaje prístino que inaugura un decir que "se hace de la sombra" (17). Sin embargo, para que esta conversación ocurra, padre e hija se vuelven otros, animales: golondrina, lechuza, zorro, oveja, perro, torcacita, bichofeo, etc. Amparados en la naturaleza, ahora ambos pueden pronunciar aquello que se "dice sin vergüenza" (25), sin "[...] esa piedra en la garganta" (25). Para Scarabelli, re-descubrir ese vínculo padre-hija- atravesado por la muerte- implica encontrarse en un afuera para conversar en "un idioma que es tan nuevo" (22) justamente porque es hablado por los animales. Instados por la muerte, los animales se multiplican para habilitar un intercambio auténtico entre padre e hija, un diálogo tranquilo: "y hablamos muy tranquilos / como si conociéramos la lengua de los pájaros" (17). De esta manera, Scarabelli niega gran parte de la tradición filosófica occidental. Como señala Derrida:

[...] (desde Aristóteles a Lacan, pasando por Descartes, Kant, Heidegger, Lévinas), todos, dicen lo mismo: el animal está privado de lenguaje. 0 , más concretamente, de respuesta, de una respuesta que hay que distinguir precisa y rigurosamente la reacción: del derecho y del poder de "responder". Y, por lo tanto, de tantas otras cosas que serían lo propio del hombre (2008: 48).

En este caso, el decir animal se postula en tanto indispensable para ambos dado que carece de las limitaciones de la lengua de los hombres. "Todo lo que un hombre no puede decir, / las cosas que tienen que quedarse calladas" (25) o "[...] todo lo que en el corazón sangra y sonríe" (21): la lengua animal aloja esos imposibles para el lenguaje humano y los vuelve enunciados.

28 Como plantea en "El río", la desaparición física del padre habilita un intercambio verbal calificado varias veces como "tranquilo" (17), despojado de preceptos y expectativas sociales, que depende del animal: "[...] y abajo quedan los animales blandos, / hablando en un idioma que es tan nuevo / que me parece que lo aprendo en un sueño / o me lo aprendo por ahí" (22). Por eso, recién después de sacarse las "corazas como de rinocerontes" (22) y las máscaras obligadas, puede irrumpir el animal para tener esa conversación con el otro nunca antes posible.

Cabe preguntarse entonces qué implica esta idea de tranquilidad reiterada varias veces a lo largo del poemario. En "Tranquilidad de hablar", el sujeto poético afirma que dicha tranquilidad al hablar proviene de saberse uno "de los que no tienen que ser oídos, / de esos a los que nadie tiene que escuchar" (17). Inmediatamente después de dar cuenta de esto el sujeto poético admite "[a]hora mismo soy como el pajarito / al que no le acierta ninguna piedra, / el pez al que no lo pescan, feliz en el agua" (17). Por un lado, la referencia a seres no escuchados podría pensarse en función de los animales mismos; sin público alguno. Por otro, se describe un circuito de comunicación cerrado, que consta de dos interlocutores: padre e hija. En todo caso, esta lengua-silbido, atesorada como propia y exclusiva, les otorga a ambos una libertad total. 
Escondido tras el juego infantil de pretender ser otro o tras un recuerdo repentino o tras ese presente poético que invita, el animal se yergue en esta obra desde una zona concebida como "exterioridad" en la cual padre e hija pueden hablar, superando las diferencias del pasado. Entonces, el silbido aprendido en la niñez deviene canto articulado desde el pico del pájaro:

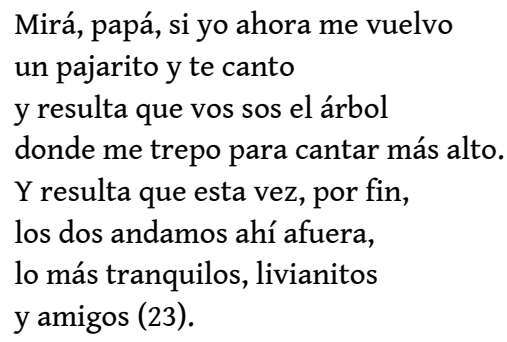

Ahora bien, por un lado, la muerte misma inaugura ese afuera para el sujeto poético: "Es verdad / está afuera todo y, se diría, / el que más afuera / de todo está / es el que está muerto" (49). Por otro, como reconoce en el poema "Otro juego", esa exterioridad existe gracias a la palabra, el acto enunciativo mismo la inscribe ${ }^{13}$ :

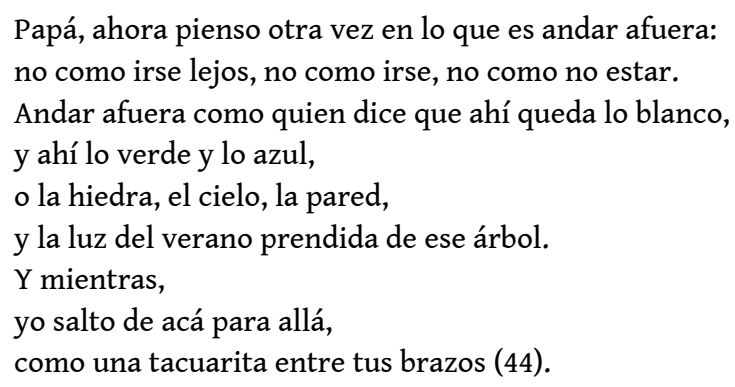

Si los animales se articulan desde ese afuera para decir aquello antes impronunciable, cabe preguntarse cómo ese sujeto poético entiende dicha exterioridad. Para Scarabelli, ese afuera asegura una particular forma de ser de todo cuanto allí se inscribe: "con esa claridad de las cosas exteriores, / con esa gracia distinta, liviana / que tiene siempre lo que está afuera" (21). Por ende, ese intercambio promovido por el animal también se teñirá de claridad, gracia y liviandad al cristalizarse allí, en ese afuera.

Ese afuera está también más allá de la lógica del mercado. En "Irse", la voz lírica explícitamente reconoce que le interesa transformarse en "esas cosas en las que nadie se fija, que nadie va a mirarlas / pensando en comprarselás" (29). Y, por eso, admite querer volverse "cualquier arbolito en las veredas / o perdido al costado de la ruta, / uno de esos perros sueltos, un pajarito / de los que se paran en los cables, / de los que se esconden entre las hojas" (29). Mientras que en el poema "Nos volvemos otros" manifiesta el mismo deseo de metamorfosearse "en todas esas cosas que pasan rápido / que nunca se quedan" (34). Al inscribirse en dicha exterioridad, el animal y su lengua se articulan por fuera de los imperativos del mercado y en función de lo transitorio, de lo efímero: o, si se quiere, en función de la experiencia poética misma. Los animales se cristalizan así en ese instante único en el cual el silbido se vuelve poesía.

Finalmente, el animal se vuelve un disruptivo trickster, y así ambos pueden eludir la muerte: "al final te escapás de la muerte / y yo me escapo con vos. / Sos como un zorrito, como una liebre, / el que hace truco a los creadores de todo" (42) ${ }^{14}$. En tanto padre e hija son "gemelos" (42), los animales se comparten: golondrinas, ovejas, liebres. Los roles también pueden compartirse e, incluso, invertirse de modo tal que "[y]o nazco de vos y después te doy a luz / como si fueras mi hijo" (42). Desde ese afuera verbal y 
animal de la poesía, el sujeto lírico logra insuflar de vida al padre que "[p]rimero se muere y luego resucita" (45) para decirse aquello que antes debía silenciarse. Resguardados ahora en esos cuerpos animales, la lección aprendida en la niñez recién ahora puede completarse cabalmente: "Entonces nacés de nuevo / me contás el secreto, / y yo lo voy silbando y cantando / muy contenta en el viento" (42) ${ }^{15}$.

Ese secreto es El arte de silbar. Los balidos de esa mansa oveja que es ahora el sujeto poétice "[...] se convierten en / las letras con que escribo" (45). El animal y su lengua se imbrican así a la escena de escritura para hacer que el padre perdido, envuelto ahora en la claridad de ese afuera, pueda todavía latir en el corazón de la poesía de su hija: “[u]na tinta de saliva de oveja, / clara como esta noche de verano / en la que te recuerdo para siempre" (45).

\section{Un idioma animal en el horizonte}

En la obra de Mairal, cuando tanto el poeta-recluta Ramón Paz como el monstruo acuático están a punto de ser "pescados" por las autoridades, el pez emerge de nuevo vuelto puro brío, imposible de capturar: "nos arrastró kilómetros huyendo / hundía tres tambores como nada / y hasta cuatro [...]" (2013: soneto 35). Con el propósito de huir de las acusaciones de asesino y caníbal, el protagonista corta la soga que lo une al gomón y, amarrado al cuerpo del colosal pez, se acopla a su travesía río arriba:

[...]

me entregué a la fuerza como un loco

me arrastró como un tren yo prefería

morirme atado al pez que condenado

hundido en una cárcel humillado

la fuerza era mi miedo mi alegría

[...] (2013: soneto 39)

En Abejas, Zoo y El arte de silbar la poesía también es impulsada centrífugamente por ese conjunto de animales mientras lidia con la muerte. Al hacerlo, la escritura se empeña en poner de manifiesto un derrotero común entre hombres y animales. Sin embargo, en estas obras, el propósito principal no es- como plantean los estudios animales- llevar a cabo una crítica radical cuestionadora del lugar central que el ser humano se ha dado a sí mismo. Más bien, en la poesía argentina contemporánea es evidente una tendencia a bogar por una palabra poética que encuentra sus posibilidades de articulación y su potencial en esos mismos animales que la propulsan. Si- como señala Giorgi-, en algunos textos latinoamericanos de la primera mitad del siglo $\mathrm{XX}$, al plantear la rebelión animal, exploran "[...] si esos modos de la voz [animal] albergan o no la potencialidad del sentido" (2011a: 172) ${ }^{16}$. Un siglo después, en la obra de estos poetas argentinos esto se da por sentado.

Las trayectorias de cada poemario terminan delineando estos idiomas animales. Como si aquello que necesita decirse- cuando el límite implacable de la muerte interrumpesolamente pudiera cristalizarse en los zumbidos de las abejas, en la llamada muda del perro, en los silbidos del dragón/serpiente o en el canto de los pájaros. Por eso, la reflexión final de la voz poética escarabajo-rinoceronte en Zoo insiste en esta facultad de este ser vivo de verse afectado o conmovido tanto por lo bueno como por lo malo. Porque, como asegura Crotto, "[d]e lo que abunda / el corazón hable la boca" (21). Ante el silencio absoluto de la muerte, el animal late vigoroso en el centro de la poesía argentina para decirla. Son esos idiomas nuevos- como propone Scarabelli- los que se 
avizoran en el horizonte de la poesía argentina hoy en día para "a su modo ilumina[r] / esas zonas siempre oscuras / en cualquier casa" (Mallol 45).

\section{BIBLIOGRAPHY}

Berger John, “¿Por qué miramos a los animales?”, Mirar, Barcelona, Editorial Gustavo Gili, 2001, p. 9-31. Traducción de Pilar Vázquez.

Cabezón Cámara Gabriela, “La última vuelta de la gauchesca”, Página 12, 1 de enero 2014. Web. Consultado 12/8/2018.

Campero Elena (2018), "Del gaucho al guacho: la orfandad mostrosa de Martín Fierro en la poesía de Óscar Fariña", Revista de Estudios Hispánicos tomo 52, n 1, marzo, St. Louis, Universidad de Washington en St. Louis, p. 199-222.

--- (s/f), "Los coletazos furiosos de El gran surubi", inédito.

Cragnolini, Mónica. “Extraños animales: la presencia de la cuestión animal en el pensamiento contemporáneo”. Revista Latinoamericana de Estudios Críticos Animales, Año I, Vol. II, octubre 2014, Buenos Aires, p. 15-33.

Crotto Alejandro, Abejas, Buenos Aires, Bajo La Luna, 2009.

Derrida Jacques, El animal que luego estoy si(gui)endo, Madrid, Editorial Trotta, 2008.Traducción de Cristina de Peretti y Cristina Rodríguez Marciel.

Fariña Óscar, El guacho Martín Fierro, Buenos Aires, Factotum ediciones, 2011.

Garcés Gonzalo. “Los escritores argentinos y la libertad”, La Nación, 7 de marzo 2014, Web. Consultado 12/8/2018.

Giorgi Gabriel (2011a), “La rebelión de los animales. Zoopolíticas sudamericanas”, Aletria: Revista de Estudos de Literatura, volumen 21, número 3, septiembre-diciembre, Universidade Federal de Minas Gerais, p. 165-177.

--- (2011b), “La vida impropia. Historias de mataderos", Boletín del Centro de Estudios de Teoría y Crítica Literaria 16, diciembre, Universidad Nacional de Rosario, p. 1-22.

--- (2014), Formas Comunes: Animalidad, cultura, biopolitica, Buenos Aires, Eterna Cadencia.

Hernández José, Martín Fierro. Buenos Aires, Ed. Losada, 1963.

Hyde Lewis, Trickster Makes This World. Mischief, Myth, and Art, New York, Farrar, Straus and Giroux, 1998.

Katchadjian Pablo, El Martín Fierro ordenado alfabéticamente, Buenos Aires, IAP, 2007.

Kohan Martín, “El Matadero”, E-misférica Bio/Zoo 10.1, invierno 2013, Web. Consultado 12/8/2018.

Ludmer Josefina, El género gauchesco: un tratado sobre la patria, Buenos Aires, Libros Perfil, 2000.

Mairal Pedro (2012), “Taller de lectura de poesía 2012”, 8 de marzo, El señor de abajo Blog, Web. Consulado el 1/3/2019. 
--- (2013), El gran surubí, Buenos Aires, Orsai.

Mallol Anahí, Zoo, Buenos Aires, Paradiso, 2009.

Scarabelli Sonia, El arte de silbar, Buenos Aires, Bajo La Luna, 2014.

Yelin Julieta, La letra salvaje: Ensayos sobre literatura y animalidad, Rosario, Beatriz Viterbo, 2015.

\section{NOTES}

1. Conviene aclarar que los sonetos, escritos en lengua coloquial, están acompañados por ilustraciones de Jorge González. Como el texto no está numerado, cuando cito sus versos he añadido entre paréntesis el soneto al cual pertenecen. Sin embargo, en el original tampoco hay indicación alguna respecto de los sonetos; es decir, se trata de un agregado mío para facilitar su ubicación.

2. Una pregunta cruciał que este ensayo no explora es por qué irrumpen los animales en la escena poética argentina con tanto ímpetu por estos años. En este sentido, cabe señalar que en el año 2010 se conmemoró el Bicentenario de la Revolución de Mayo y, por ende, los clásicos argentinos del siglo XIX y su constelación animal son sometidos a un intenso trabajo de re-escritura. En poesía, además de la obra de Mairal, pienso en El guacho Martín Fierro (2011) de Óscar Fariña y su prolífero imaginario animal (Campero 2018: 203). El Martín Fierro ordenado alfabéticamente (2007) de Pablo Katchadjian completa la trilogía, pero se trata de un proyecto muy diferente. En narrativa, por ejemplo, puede mencionarse "El Matadero" (2009) de Martín Kohan.

3. Para un estudio exhaustivo de esta cuestión y del imaginario animal en El gran surubí de Pedro Mairal consultar mi ensayo inédito "Los coletazos furiosos de El gran surubi". Como la obra de Mairal es una re-escritura del clásico de Hernández, las ramificaciones e implicaciones son colosales (como el surubí mismo) y exceden el alcance de estas páginas.

4. Sorprende mucho que El gran surubí haya pasado casi desapercibido por la crítica; dentro de las pocas excepciones pueden mencionarse los artículos "La última vuelta de la gauchesca" de Gabriela Cabezón Cámara y "El escritor argentino y la libertad" de Gonzalo Garcés. Para Cabezón Cámara “[...] El gran surubí es, a mi juicio, por su belleza, por la originalidad con que retoma y reinventa los tópicos del siglo XIX con la furia del XXI, por la potente contemporaneidad de la pesadilla que relata y de la lengua que construye, por esa música que provoca una lectura extática, uno de los textos más poderosos de lo que podría describirse como un nuevo ciclo de vuelta a la gauchesca". Para esta escritora es en "la resucitación de la gauchesca que radica la fascinación que provoca esta novela". Mientras que Garcés reflexiona acerca del tema de la libertad en la literatura argentina y, por eso, trae a colación esta obra de Marial dentro de su recorrido.

5. En su blog "El señor de abajo", Mairal promociona el "Taller de lectura de poesía 2012", dictado junto con Crotto, a celebrarse en marzo de 2012. Justamente, el tema del último de los ocho encuentros es "poemas de animales". Es decir, se trata también de un tema de reflexión y discusión compartido por ambos. Asimismo, cuando Mairal está a cargo de la serie curada del blog de la editorial Eterna Cadencia, selecciona poemas con animales para cada una de las cuatro entradas: a) "Entonces en las aguas de Conchán" del poeta peruano Antonio Cisneros (entrada del 14/7/2015), b) "La mantis religiosa", "La oruga" y "El lenguado" del poeta peruano José Watanabé (entrada del 21/7/2015), c) "Epifanía del perro" del poeta argentino César Memet (entrada del 
28/7/2015 en co-autoría con Crotto) y d) "El tigre" del poeta argentino Enrique Banchs, "Oda a la pantera negra" y "Oda al gato" del chileno Pablo Neruda (entrada del 4/8/2015).

6. El poema "Zoológico" funciona como contrapunto de toda la colección dado que, por un lado, muestra animales en cautiverio en un espacio citadino y, por otro, el sujeto poético sí deja entrever el impacto negativo que le produce esa visita. Tanto es así que se auto-censura cuando llega a la jaula del chimpancé, intentando truncar la reflexión que dicha experiencia le suscita: "Y el chimpancé a treinta centímetros del vidrio / nos mira para adentro sin relámpago, / con la melancolía laminada como cera / en los ojos abiertos y velados... ¡y basta! / que venimos a ver a los / animales: / el cocodrilo cruel y quieto, tronco o roca, / [...] (32). La visita al zoológico es tan desoladora como la mirada vacía devuelta por el chimpancé. 0 , si se quiere, doblemente desoladora porque hasta cierto punte- duplica la mirada inerte que tenía el sujeto poético en el poma inaugural.

7. Idéntica actitud adopta el sujeto poético al observar la ecografía de su futura hija en el poema "Mira el padre joven la ecografía donde sumergida en el líquido amniótico late su hija de cinco meses, y le habla".

8. Se trata del mismo poema especificado en la nota al pie anterior.

9. La cita proviene de Journal du voleur de Jean Genet: "Une curiese bête apparaîtrait si chacune de mes émotions devenait l'animal qu'elle suscite”.

10. En el ámbito latinoamericano deben mencionarse las propuestas de Juan José Arreola, Jorge Luis Borges y Julio Cortázar.

11. La dedicatoria dice: "Para Nazareno, Ireneo e Isidoro: niños".

12. Los poemas llevan por título números, contribuyendo a la idea de ritmo, de vida en constante movimiento.

13. En el poema final "La exterioridad", la voz lírica explícitamente reconoce esta cuestión al aseverar que: "porque empezás / hablando y cuando / te descuidaste, / todo está afuera" (50).

14. El poema se titula "Trickster" de allí el empleo de dicha categoría. A la hora de definir la categoría de "trickster" se puede afirmar que: "En resumen, el trickster es el que cruza límites. [...] la mejor manera de describirlo es simplemente decir que es en el límite donde hallaremos al trickster: a veces dibujando la línea, a veces cruzándola, otras veces borrándola o desplazándola, pero siempre allí, es el dios del umbral en todas sus formas" (Hyde 1998: 7, mi traducción). ["In short, trickster is a boundary-crosser. [...] the best way to describe trickster is to say simply that the boundary is where he will be found- sometimes drawing the line, sometimes crossing it, sometimes erasing or moving it, but always there, the god of the threshold in all its forms" (Hyde 1998: 7)]

15. El poema "Trickster II", continúa con la fuga de padre e hija, quienes al burlar la muerte festejan de una forma que trae a colación al perro Arumi (43), a la gata Negrita (43), al perro Cordero (43), a los bichofeos (43) y a las torcacitas (43).

16. Giorgi examina "Los caballos de Abdera” (1906) de Leopoldo Lugones, “Juan Darién' (1926) de Horacio Quiroga y "Mi tío el yaguareté" (escrito hacia 1950 y publicado en 1960) de João Guimarães Rosa. 


\section{ABSTRACTS}

In the poetry books Abejas (2009) by Alejandro Crotto, Zoo (2009) by Anahí Mallol, and El arte de silbar (2014) by Sonia Scarabelli, animals, death, and words become key articulators of Argentinian poetry published within the last ten years. In these works, the poetic voice is confronted with the liminal experience of death and chooses to expresses itself through these animals' bodies. When facing death, these animals facilitate poetic enunciation. Hence, these poetry books put forward "a language that is so new" (Scarabelli 2014: 22) precisely because it belongs to animals.

En los poemarios Abejas (2009) de Alejandro Crotto, Zoo (2009) de Anahí Mallol y El arte de silbar (2014) de Sonia Scarabelli, los animales, la muerte y la palabra se revelan como nudos articuladores de la práctica poética argentina de los últimos diez años. En estas obras, la palabra poética, cercada siempre por la experiencia liminar de la muerte, encalla en esos cuerpos animales para decirse. Frente a la muerte, son los animales quienes garantizan la posibilidad de enunciación misma para la poesía. De esta manera, estos poemarios alojan "un idioma que es tan nuevo" (Scarabelli 2014: 22) justamente porque les pertenece a los animales.

Dans les recueils de poèmes Abejas (2009) d'Alejandro Crotto, Zoo (2009) d'Anahí Mallol et El arte de silbar (2014) de Sonia Scarabelli, les animaux, la mort et la parole apparaissent comme des piliers centraux de la pratique poétique argentine la plus récente. Dans ces œuvres, la parole poétique, toujours proche de l'expérience liminaire de la mort, utilise les corps des animaux afin de s'exprimer. Face à la mort, ce sont les animaux qui garantissent la possibilité d'énonciation pour la poésie. C'est ainsi que dans ces recueils de poèmes se trouve "un langage qui est si neuf" (Scarabelli 2014: 22) précisément parce qu'il appartient aux animaux.

\section{INDEX}

Mots-clés: animaux, poésie contemporaine argentine, mort, langage des animaux, voix poétique Palabras claves: animales, poesía argentina contemporánea, muerte, idioma animal, voz poética Keywords: animals, contemporary Argentinian poetry, death, animal language, and poetic voice

\section{AUTHOR}

\section{ELENA CAMPERO}

McDaniel College

mcampero@mcdaniel.edu 